\title{
Treatment of focal epithelial hyperplasia with topical imiquimod
}

\section{Fokal epitelyal hiperplazinin topikal imikimod ile tedavisi}

\author{
Emine Dasbasi ${ }^{1}$, Sirin Yasar $^{1}$, Pembegul Gunes ${ }^{1}$ \\ ${ }^{1}$ Dept. of Dermatology, Haydarpasa Numune Training and Research Hospital, Istanbul, Turkey
}

Dear editor,

Focal epithelial hyperplasia (FEH-Heck disease) is a rare disorder caused by specific types of HPV. It mainly involves oral mucosa, and children are affected more frequently. It may persist for years, producing a significant reduction in quality of life. Several treatment modalities such as surgical excision, laser ablation, cryotherapy, electrocauterization, topical, intralesional or systemic interferon, and systemic retinoic acid have been used with variable results and many side effects. ${ }^{1}$ In this report, we present a 5-year-old child who has painless lumps in his mouth for one year.

A 5-year-old boy presented with a 1-year history of painless lumps in his mouth. His general health was good. Family history revealed no similar oral lesions. His parents reported that he slept with his mouth open and frequently bit the lesions while eating. Physical examination showed multiple numbers of (approximately 40) mucosa-colored, soft, discrete, flat pap- ulonodules, 0.2 to $0.8 \mathrm{~cm}$ with lobulated and verrucous surfaces, which were localized on the hard palate, bilateral buccal mucosa, and inner surfaces of upper and lower lips (Fig. la,b,c). The histologic examination was consistent with FEH (Fig. 2a,b). All of the lesions were treated with $5 \%$ imiquimod cream three nights a week for 16 weeks. Complete blood cell count and biochemical analyzes were normal before and after treatment. No serious side-effects were observed. The patient has remained disease-free during 1-year of follow-up (Fig. 3a,b).

Focal epithelial hyperplasia may heal within years by itself. The disease is generally of asymptomatic nature, however it may cause discomfort due to dysfunction, traumatization and unpleasant cosmetic appearance caused by the lesions. Moreover, malignant transformation has been reported in long-term FEH cases associated with HPV-24. ${ }^{2}$ In our patient, because of the resistance of previous treatments, long-standing and widespread lesions, we have

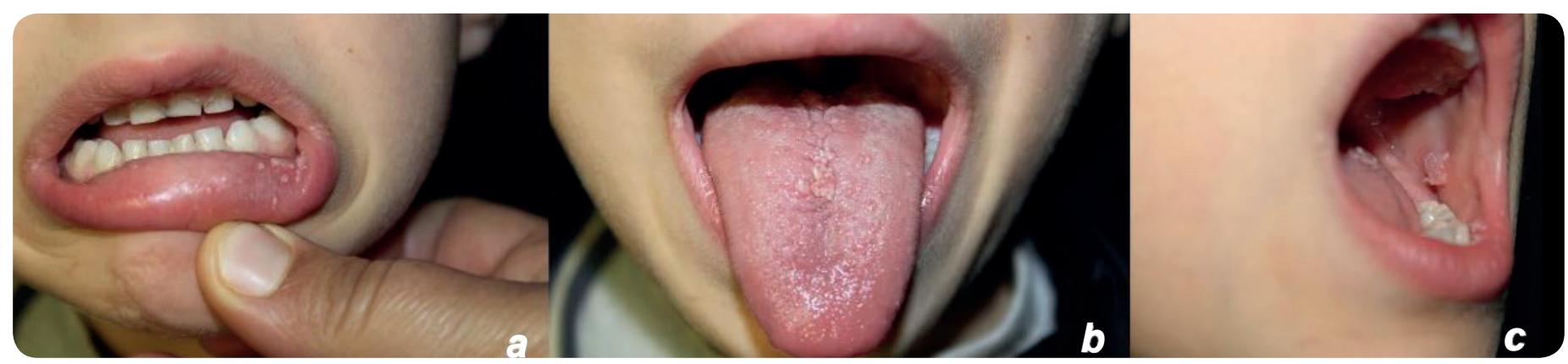

Fig. 1a,b,c. Multiple mucosa-colored, soft, discrete, flat papulonodules localized on the hard palate, bilateral buccal mucosa, and inner surfaces of upper and lower lips

Corresponding author: Emine Dasbasi, Dept of Dermatology, Haydarpasa Training and Research Hospital, Istanbul, Turkey. Phone: +90 2165423200 E-mail: eminedasbasi@gmail.com

Received: 24 August 2018 Accepted: 2 October 2018

Conflicts of Interest: None 


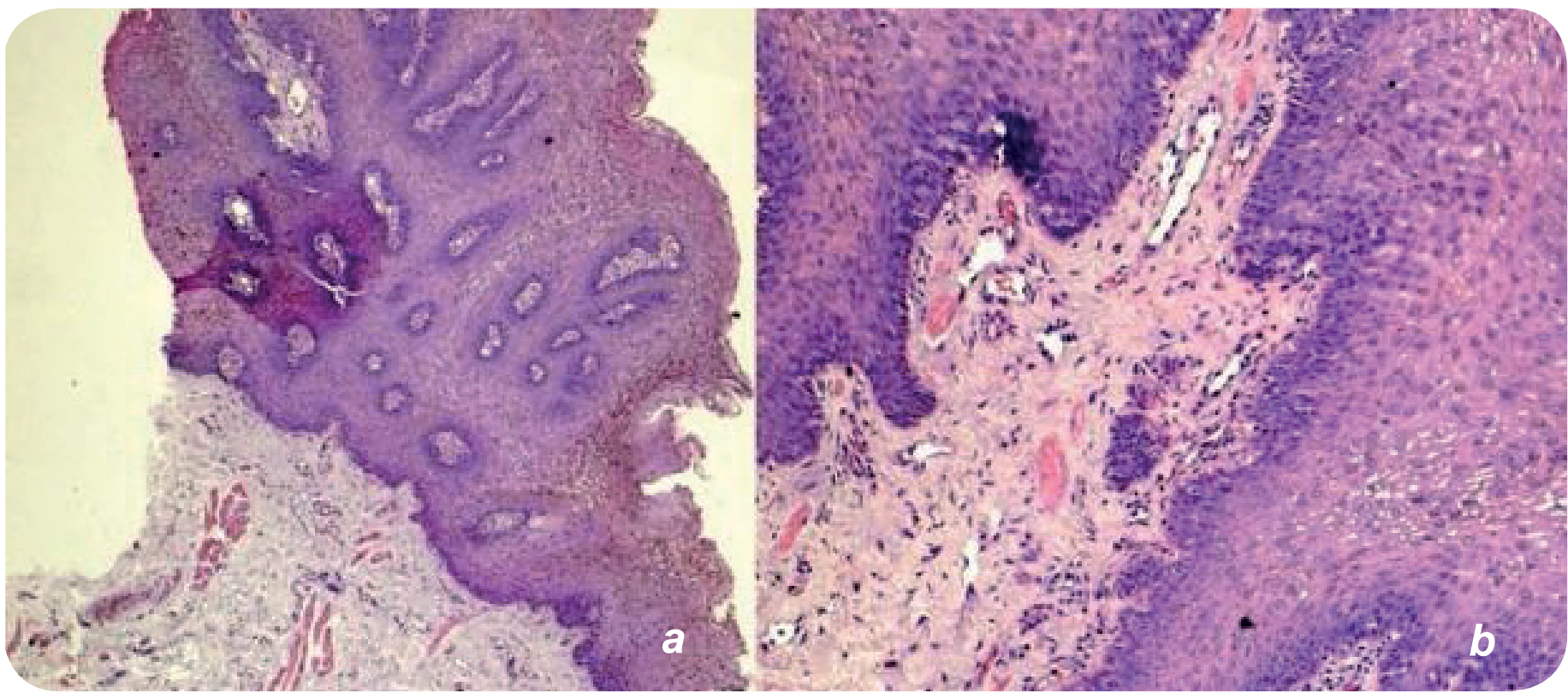

Fig. 2a,b. A squamous epithelium with focal parakeratosis, hyperkeratosis, acanthosis, koilocytosis, verrucous proliferation and marked papillomatosis (H.E. x40, x100)

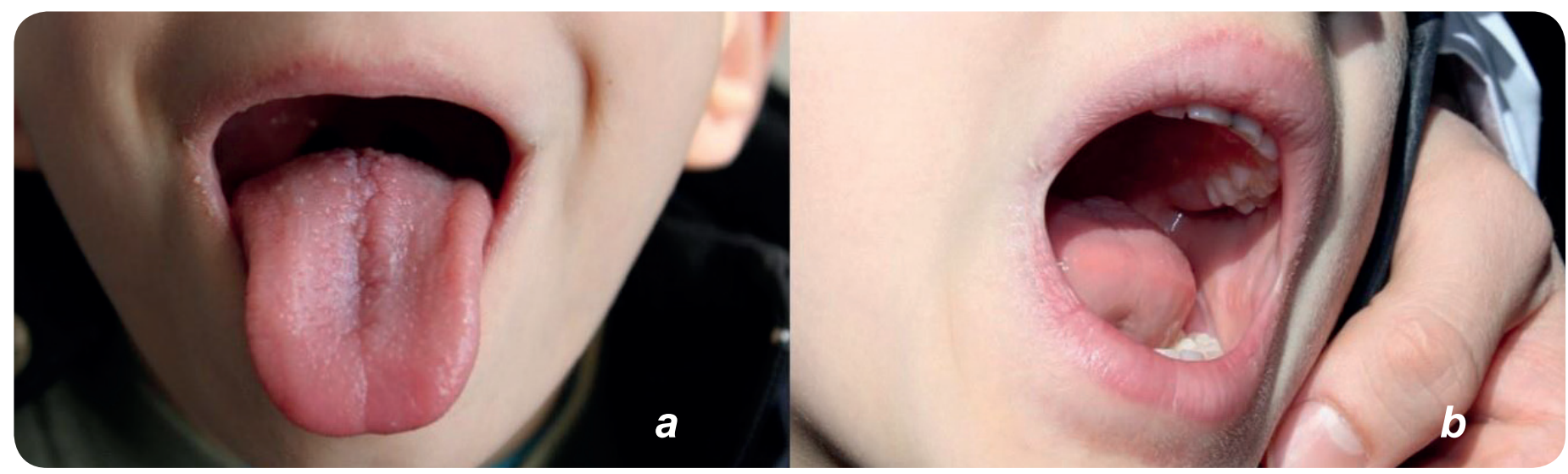

Fig. 3a,b. The healing after topical imiquimod treatment

considered that the possibility of self-healing was low. The lesions of FEH disappeared after four months of imiquimod treatment. Moreover, the lesions did not recur for a relatively long follow-up period. Therefore, imiquimod may be an effective agent in the treatment of FEH. Topical imiquimod may be a safe, non-invasive, and successful treatment option for pediatric patients with FEH. We suggest that the painless, easy, and self-applicable treatment modalities will help to increase the patient compliance.

\section{References}

1. Kose O, Akar A, Safali M, et al. Focal epithelial hyperplasia treated with interferon alpha-2a. J Dermatol Treat 2001;12:111-3.

2. Niebrügge B, Villiers E, Gerlach K, Franke I, Gollnick H. Demonstration of HPV 24 in long-standing Heck's disease with malignant transformation. European Journal of Dermatology 1999;9:477-9. 